\title{
PORTAL DA BNB: \\ RELATO DA EXPERIÊNCIA DO PROCESSO DE CRIAÇÃO, ORGANIZAÇÃO E PLANEJAMENTO DO PORTAL DA BIBLIOTECA NACIONAL DE BRASÍLIA
}

\author{
REPORT OF EXPERIENCE IN THE PROCESS OF CREATION, ORGANIZATION AND \\ PLANNING OF THE PORTAL SITE OF THE NATIONAL LIBRARY OF BRASÍLIA
}

\author{
Vanessa Barbosa da Silva ${ }^{1}$ \\ Flávia Marta Camarano Salim ${ }^{2}$
}

\begin{abstract}
Resumo: Relato da experiência de implementação do Portal da Biblioteca Nacional de Brasília (BNB), que utiliza a segmentação de mercado e oferece produtos e serviços online de acordo com a necessidade de informação de seus públicos. Com essa iniciativa, o Portal da BNB mostra uma interface interativa e auto-explicativa, reunindo informações pertinentes para cada grupo de usuários atendidos pela instituição. Por fim, apresenta todos os detalhes do projeto, desde a sua concepção até o seu lançamento na web.
\end{abstract}

Palavras-chave: Portal. Arquitetura de sistema. Biblioteca Nacional.

Abstract: This paper is a report of experience of implementing the Portal Site of the National Library of Brasilia (BNB - Biblioteca Nacional de Brasília), which applies market segmentation and offers online services and products according to the needs of the public regarding information. With this initiative, the BNB Portal Site displays an interactive and self-explainable interface, gathering pertinent information to each group of users assisted by the institution. At last, the paper presents each detail of the project, from its conception up to the release of the internet site.

Keywords: Portal site. Systems architecture. National Library.

\footnotetext{
${ }^{1}$ Mestranda em Ciência da Informação pela Universidade de Brasília; Pós-graduada em Biblioteconomia pela FIJ Bacharel em Biblioteconomia pela Universidade de Brasília. Biblioteca Nacional de Brasília. Brasília, DF, Brasil. Email: vanessavbs@hotmail.com

${ }^{2}$ Relações Públicas. Especialista em Gestão de Comunicação nas Organizações. Analista de Políticas Públicas e Gestão Governamental do Governo do Distrito Federal. Biblioteca Nacional de Brasília. Brasília, DF, Brasil. E-mail: flavia@bnb.df.gov.br

Enviado em: 21/10/2011 - Aceito em: 16/12/2012.

\begin{tabular}{l} 
(C) Rev. digit. bibliotecon. cienc. inf. \\
\hline
\end{tabular}
}




\section{INTRODUÇÃO}

A Biblioteca Nacional de Brasília (BNB) é a primeira grande biblioteca híbrida do país no século XXI. As atividades da BNB estão orientadas para o atendimento interno - o que denominamos disponibilidade documentária, baseada em acervos, produtos e serviços diretos aos nossos frequentadores - e para o atendimento externo, via web, que cognominamos acessibilidade informacional. $\mathrm{Na}$ era do ciberespaço, o acesso a fontes externas extrapolam as locais, ampliando consideravelmente a capacidade de atendimento (MIRANDA, 2009).

Com base nesta diretriz o portal da BNB (www.bnb.df.gov.br) utiliza a internet para organizar e disponibilizar serviços de busca de documentos e informações em fontes externas para atender os seus usuários, além de promover a comunicação e a interação com os seus públicos, transformando-se no cartão de visitas institucional no ambiente virtual.

A partir do trabalho multidisciplinar de um grupo de servidores da BNB, que reuniu profissionais nas áreas de biblioteconomia, comunicação social e tecnologia da informação, a arquitetura e o projeto do portal da BNB foram concebidos priorizando a oferta de produtos e serviços online para um público segmentado.

Diante das limitações financeiras, optou-se por utilizar um sistema de administração de conteúdo gratuito e de fácil operação - Joomla - que, por meio de seus aplicativos, tornou o portal mais intuitivo, interativo e auto-explicativo, estabelecendo uma interface de sucesso entre a BNB e os internautas.

A experiência da criação e organização do conteúdo do Portal é apresentada neste artigo onde estão reunidos todos os detalhes do projeto, desde a sua concepção até o seu lançamento na web.

\section{METODOLOGIA E PLANEJAMENTO}

A versão anterior da página da BNB na internet vigorou no período de setembro de 2008 a dezembro de 2009. Em função da inauguração da instituição ocorrida em 12 de dezembro de

\begin{tabular}{l|l|l|l|l|l|l}
\hline (C) Rev. digit. bibliotecon. cienc. inf. & Campinas, SP & v.11 & n.1 & p.93-110 & jan./abr. 2013 & ISSN 1678-765X \\
\hline
\end{tabular}


2008, o site foi estruturado de forma limitada, tendo em vista a pouca oferta de serviços e informações produzidas pela instituição. Em março de 2009, diante da necessidade de se dialogar melhor com a sociedade e a abertura de novos produtos e serviços à população, foi desenvolvido o projeto para a implementação de seu novo portal.

Para fundamentar este projeto foram analisadas a literatura científica sobre o desenvolvimento de sites de unidades de informação e observados empiricamente os portais de algumas bibliotecas, em especial, a Biblioteca de Alexandria ${ }^{3}$.

O portal da Biblioteca de Alexandria se distingue, entre os outros portais semelhantes no Brasil e exterior, pela forma de organização do conteúdo e pela segmentação do público com base nos usuários que são predominantemente atendidos pela biblioteca.

Acerca da opção pela segmentação, Suaiden (2000, p. 60) afirma que no caso específico das bibliotecas, as técnicas de segmentação de mercado são justificáveis, tendo em vista a grande diversidade de interesses informacionais da comunidade e a limitação financeira das instituições para o atendimento das diferentes necessidades de seus públicos.

Esta segmentação foi adotada no portal da BNB, com o objetivo de atender às expectativas dos usuários que buscam, prioritariamente, por seus produtos e serviços online, segundo levantamento estatístico realizado, por meio do Google Analytics, sobre os conteúdos mais acessados do site.

No tocante à literatura científica foi de suma importância a análise do estudo desenvolvido por Amaral e Guimarães (2002) sobre os sites de bibliotecas. As autoras propuseram uma classificação para as funções dos sites de bibliotecas em informacional, promocional, instrucional, referencial, de pesquisa e de comunicação.

Através dos resultados destas pesquisas e da classificação proposta por Amaral e Guimarães (2002), foi realizada uma análise da versão anterior do site com o objetivo de verificar quais funções o site da BNB atendia e quais eram as suas deficiências. A partir desta

\begin{tabular}{|c|c|c|c|c|c|c|}
\hline (C) Rev. digit. bibliotecon. cienc. inf. & Campinas, SP & v.11 & n.1 & p.93-110 & jan./abr. 2013 & ISSN 1678-765X \\
\hline
\end{tabular}


metodologia, foi possível implementar no novo portal todos os itens propostos no estudo apresentado pelas autoras mencionadas.

\section{A ESCOLHA DA FERRAMENTA}

Desde o início, foi proposto pela equipe que o portal da BNB deveria ser implementado utilizando-se ferramentas e aplicativos de simples manutenção, preferencialmente sem custos, uma vez que este foi um dos principais problemas detectados na versão anterior.

A equipe buscou então uma tecnologia de linguagem acessível, de fácil compreensão, o que permitiu, por conseguinte, a autonomia na publicação dos conteúdos. A escolha da ferramenta Joomla - sistema de administração de conteúdos (CMS - Content Manager System) que possibilita a edição e publicação online de informações em sites na Internet, muito utilizado para confecção de portais simples ou complexos - atendeu às nossas principais necessidades: autonomia para a inserção do conteúdo com rapidez e segurança e interface gráfica (layout) interativa, leve e de fácil navegação.

Escolhida a ferramenta, a equipe do portal recebeu treinamento inicial de uma semana para conhecimento do sistema e, ao longo de 2009, o acompanhamento na inserção de conteúdos e manutenção do site por parte dos profissionais da área de Tecnologia da Informação, participantes do projeto de reestruturação da página da BNB.

\section{GERENCIAMENTO DO PORTAL}

A administração de um portal é uma atividade complexa que demanda tempo, esforço e dedicação de uma equipe multidisciplinar. Servidores da BNB com formação em biblioteconomia (05 profissionais) e comunicação social - relações públicas (01 profissional), além de consultores da área de tecnologia da informação (02 profissionais) desenvolveram o novo portal da BNB utilizando como base tecnológica a ferramenta Joomla, já mencionada.

A equipe do portal administra livremente suas páginas com autonomia de inserção e alteração do conteúdo. Com o objetivo de descentralizar o gerenciamento das informações do

\begin{tabular}{l|l|l|l|l|l|l}
\hline (C) Rev. digit. bibliotecon. cienc. inf. & Campinas, SP & v.11 & n.1 & p.93-110 & jan./abr. 2013 & ISSN 1678-765X \\
\hline
\end{tabular}


portal, a alimentação de conteúdo foi dividida entre os membros da equipe que desenvolveu o projeto onde cada profissional ficou responsável por uma determinada seção do portal. O profissional de relações públicas gerencia as seções "Conheça a BNB", "Eventos", "Notícias" e "Sala de imprensa". Cabe aos bibliotecários de referência o papel de administrar a seção "Atendimento ao Usuário" e o subsite "BNB Pesquisador". A seção "Produtos e Serviços para você", que contem os subsites "BNB Bibliotecário", "BNB Criança", "BNB Comunidade" e "BNB Jovem", é gerenciada por bibliotecários do setor de Processamento Técnico.

Apesar da equipe responsável por administrar o portal desenvolver atividades paralelas na $\mathrm{BNB}$, não podendo se dedicar integralmente às demandas do portal, a página é constantemente monitorada e avaliada, no sentido de assegurar que todos os esforços empreendidos durante a fase de planejamento sejam efetivamente concretizados. Reuniões de acompanhamento e de avaliação foram realizadas durante a execução do projeto - março a novembro de 2009, e após o seu lançamento oficial que ocorreu em 12 de dezembro do mesmo ano, data em que a BNB celebrou um ano de abertura ao público.

\section{ESTRUTURAÇÃO DO CONTEÚDO DO NOVO PORTAL}

Com base nas pesquisas realizadas e nos estudos descritos no projeto, a equipe definiu as informações que deveriam constar no novo portal da BNB e optou por reunir em menus principais, localizados na barra superior da tela, informações de fácil acesso para que o visitante permanecesse na página e encontrasse de forma rápida e em poucos cliques, as informações de seu interesse (Figura 1).

Os conteúdos foram assim distribuídos:

a) Conheça a BNB, eventos e sala de imprensa

A Assessoria de Comunicação da BNB, além de acompanhar e apoiar o desenvolvimento do conteúdo do portal como um todo, ficou com a incumbência de gerenciar três importantes seções: Conheça a BNB, Eventos e Sala de Imprensa.

\begin{tabular}{l|l|l|l|l|l|l}
\hline (C) Rev. digit. bibliotecon. cienc. inf. & Campinas, SP & v.11 & n.1 & p.93-110 & jan./abr. 2013 & ISSN 1678-765X \\
\hline
\end{tabular}


A seção "Conheça a BNB" foi estrategicamente posicionada ao lado do ícone "Início" na barra de navegação global, pois seu objetivo é dar as boas-vindas aos internautas, informar sobre a história, localização, parceiros, instalações físicas e estatísticas. A ideia principal é que o visitante do portal tenha todas as informações sobre a instituição ao seu alcance de forma rápida, transparente, lógica e em linguagem acessível.

A seção "Eventos" foi criada para informar sobre as atividades culturais e educacionais que ocorrem na instituição, tais como palestras, exposições, cursos e outras atividades diversificadas, tendo em vista a procura por este tipo de informação registrada na versão anterior do site.

As categorias desta seção foram determinadas em: Agenda do mês, Como agendar o seu evento na BNB e Eventos realizados. Além do visitante ter acesso à programação do mês na $\mathrm{BNB}$, ele tem à sua disposição informações sobre como utilizar os espaços da instituição para realizar o seu evento, e o registro de alguns eventos mais significativos já realizados. É importante ressaltar que, tanto o menu "Eventos", quanto o "Sala de Imprensa", foram posicionados no final da barra global de navegação, pois a área central da barra foi destinada aos produtos e serviços que a biblioteca oferece ao usuário e comunidade, que é a razão de ser da instituição e ponto de maior interesse dos internautas.

Já a seção "Sala de Imprensa", criada para o atendimento das necessidades dos órgãos de imprensa, tem por objetivo fornecer dados que subsidiem o trabalho dos jornalistas em relação à BNB como ação estratégica para formar o conceito de instituição acessível e transparente junto aos meios de comunicação. As categorias foram assim determinadas: Notícias, Banco de imagens (imagens institucionais disponíveis para download), Atendimento à imprensa (indicação de fontes da BNB para entrevista), BNB na mídia (publicações na imprensa sobre a BNB), BNB em números (dados estatísticos), Documentos técnicos (manuais) e Fale conosco (canal aberto para solicitação de informações adicionais). 
b) Acervo

$\mathrm{A}$ BNB ainda não tem acesso às estantes nem permite (ainda) consultas em seu acervo bibliográfico que está sendo catalogado, constituindo-se em caso único de biblioteca aberta sem acervo disponível para o público. O processamento técnico das obras foi iniciado em 2009, atendo-se à organização de duas grandes coleções, uma popular e uma especializada em temas brasileiros, de ampla abrangência às áreas do conhecimento.

Segundo Miranda (2009, p. 22), muita gente achou que a Biblioteca só deveria abrir suas portas quando pudesse garantir a disponibilidade documentária, isto é, o acesso aos livros e a outros documentos físicos, mas optou-se fazê-lo, e o resultado confirma o que se previa: que muita gente não frequenta biblioteca por causa da consulta e do empréstimo de livros. Muitos querem um local para estudar sozinho ou em grupo, usando os próprios livros, cadernos, anotações e/ou valendo-se de pesquisas na internet. Ou seja, na prática, os livros, revistas etc., funcionam como suportes para a prestação de serviços, em vez de serem a razão da frequência às bibliotecas. Em outras palavras, a biblioteca sendo uma fonte ou meio de obter informação e não um local exclusivamente para consulta a acervos bibliográficos.

Em seu portal, a BNB presta informações sobre o acervo, a organização das obras e suas coleções. Futuramente, colocará a disposição de seus usuários o catálogo online, para consulta e reservas de suas obras para o qual se espera um grande número de acessos diretos.

\section{c) Atendimento ao Usuário}

As informações apresentadas na seção "Atendimento ao Usuário” foram elaboradas com o intuito de promover a rapidez no atendimento, orientando-os acerca das atividades cotidianas de prestação de serviços oferecidos pela instituição.

Com uma linguagem acessível, a seção é composta por orientações gerais, informações sobre acessibilidade de pessoas com necessidades especiais ao prédio da BNB; orientações a

\begin{tabular}{l|l|l|l|l|l|l}
\hline (C) Rev. digit. bibliotecon. cienc. inf. & Campinas, SP & v.11 & n.1 & p.93-110 & jan./abr. 2013 & ISSN 1678-765X \\
\hline
\end{tabular}


respeito da visita guiada e da rede sem fio (wireless); os procedimentos do setor de AchadoS e Perdidos; informações sobre o Posto avançado da Mala do Livro e os serviços de inclusão digital. Para facilitar o atendimento no ambiente virtual, o usuário dispõe de perguntas frequentes e do fale conosco.

Esta seção é uma das que recebe o maior número de acessos dos visitantes, razão pela qual a equipe responsável pela alimentação de conteúdo busca atualizá-la sempre que ocorre alguma reorientação administrativa referente ao atendimento e regulamentos da BNB.

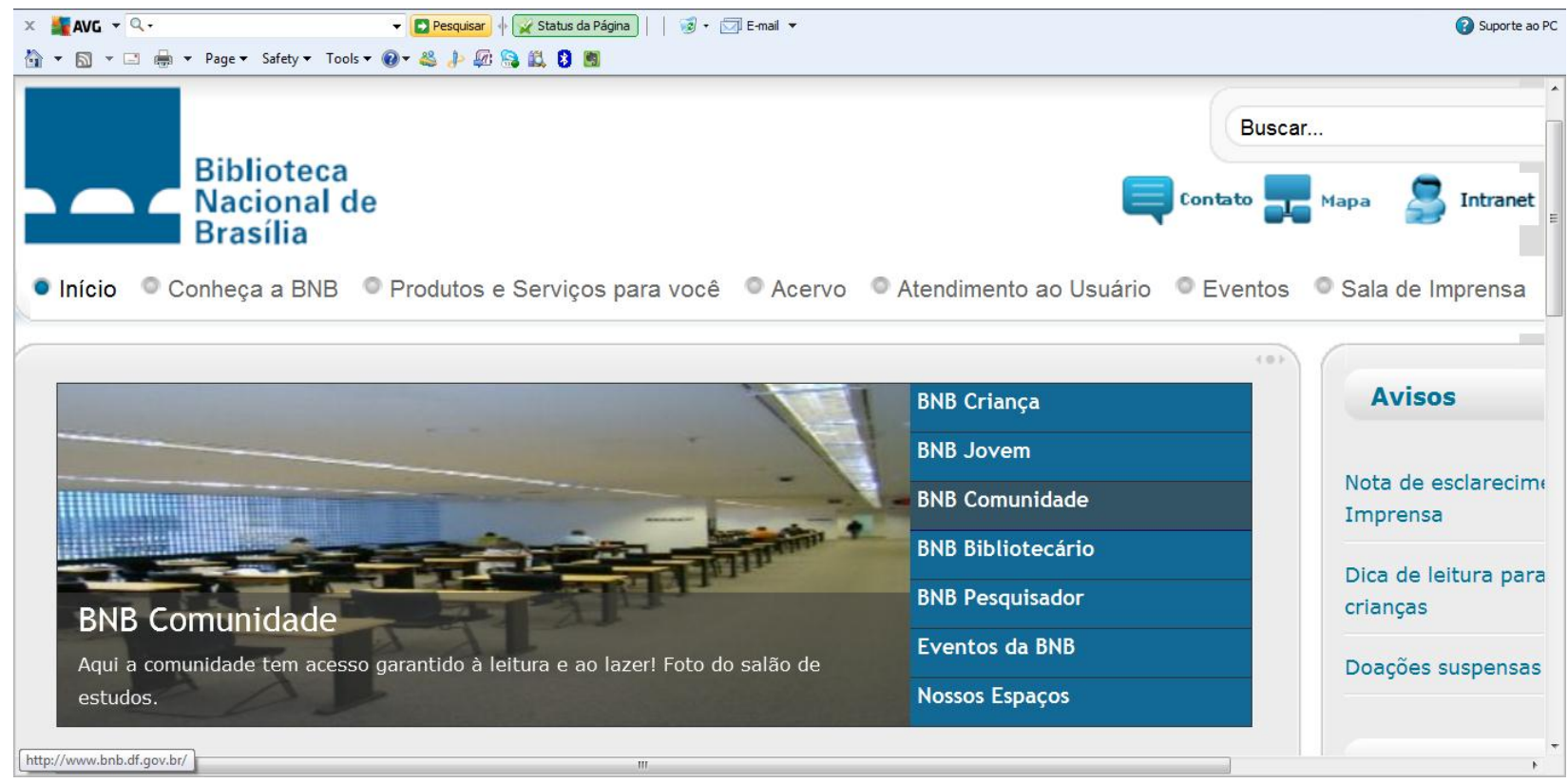

Figura 1 - Imagem Parcial da página inicial do Portal da $\mathrm{BNB}^{4}$

\footnotetext{
${ }^{4}$ Fonte: Portal da Biblioteca Nacional de Brasília (www.bnb.df.gov.br)
}

\begin{tabular}{l|l|l|l|l|l|l}
\hline (C) Rev. digit. bibliotecon. cienc. inf. & Campinas, SP & v.11 & n.1 & p.93-110 & jan./abr. 2013 & ISSN 1678-765X \\
\hline
\end{tabular}




\section{SEGMENTAÇÃO DO PÚBLICO}

\section{Produtos e serviços para você}

A Biblioteca Nacional de Brasília está aberta a todos os usuários, independente de faixa etária, nível social ou necessidade informacional. O acesso físico à BNB se dá com prévia identificação e os públicos que frequentam a BNB são diversificados dentre os quais comunidade, pesquisadores, servidores públicos, estudantes, entre outros.

Para atender a um público tão diversificado no ambiente online, a equipe optou por segmentar os usuários da BNB criando a seção "Produtos e Serviços para você", distribuindo os conteúdos informacionais em 05 (cinco) grandes grupos, a saber: BNB Bibliotecário, BNB Criança, BNB Comunidade, BNB Jovem e BNB Pesquisador. Desta forma, foram reunidas as informações pertinentes para cada grupo de usuários e tão logo acesse o site, o usuário tem a opção de escolher em qual grupo ele mais se identifica e obter as informações de seu interesse. Este é o grande diferencial do portal da BNB (Figura 2).

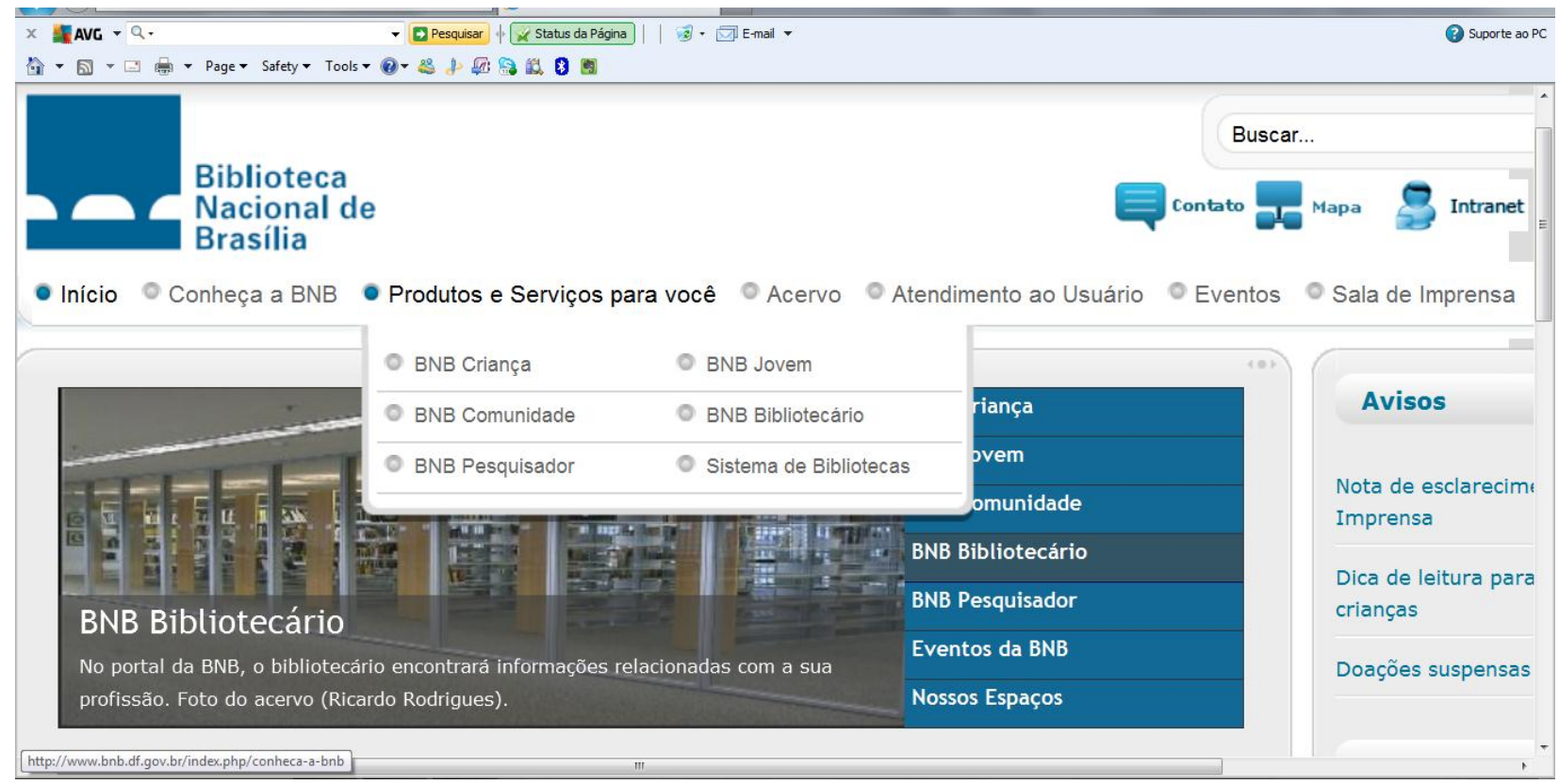

Figura 2 - Menu da seção Produtos e Serviços para você ${ }^{5}$

${ }^{5}$ Fonte: Portal da Biblioteca Nacional de Brasília (www.bnb.df.gov.br)

\begin{tabular}{l|l|l|l|l|l|l}
\hline (c) Rev. digit. bibliotecon. cienc. inf. & Campinas, SP & v.11 & n.1 & p.93-110 & jan./abr. 2013 & ISSN 1678-765X \\
\hline
\end{tabular}




\section{BNB Bibliotecário}

O objetivo do subsite "BNB Bibliotecário" é ser um local de referência para o profissional bibliotecário no Brasil. A escolha por este segmento deve-se, entre outros fatores:

- à parceria da instituição com as entidades de classe da Biblioteconomia (CRB e ABDF) com o intuito de fortalecer a presença da $\mathrm{BNB}$, tornando-a a biblioteca pública de referência no Distrito Federal;

- à realização de eventos na BNB voltados para esse público (Ciclo de Conferências em Biblioteconomia, Ciência da Informação e Comunicação); e,

- às necessidades de informação dos profissionais que trabalham na $\mathrm{BNB}$, que em sua maioria são Bibliotecários.

A seleção do conteúdo postado no subsite foi feita a partir das necessidades levantadas junto aos bibliotecários da BNB e a partir de pesquisas em sites da área de Biblioteconomia. $\mathrm{O}$ critério utilizado para oferecer produtos e serviços consiste na preocupação com a atualização deste profissional, que deve ser constante, tendo em vista que o seu principal objeto de trabalho é a informação.

\section{BNB Criança}

Depois de várias reuniões e pesquisas para definição de quais públicos seriam atendidos no portal, a equipe optou pelo público infantil com o intuito de incentivar o hábito da leitura e de pesquisa desde a infância, ampliando, por conseguinte, as oportunidades culturais e informacionais por meio do acesso às obras de qualidade.

Outro fator relevante que corroborou para a escolha deste segmento é a existência de um espaço físico específico para atender crianças de 5 a 10 anos na BNB, com atividades específicas desenvolvidas por uma equipe de pedagogos e destinadas ao atendimento à comunidade e ao agendamento escolar. 
Para constituir o acervo eletrônico foram escolhidos temas e conteúdos educativos que favorecessem ao desenvolvimento da criatividade e do conhecimento, através de jogos, brincadeiras, áudios e vídeos. Além deste serviço, são oferecidos conteúdos relacionados à saúde e à cidadania com o objetivo de informar às crianças sobre seus direitos e deveres, conceitos de cidadania, além dos cuidados que devem ter com a saúde.

Os conteúdos que integram o subsite "BNB Criança" foram pesquisados e colhidos na internet, em domínio público, além de serem fruto de parcerias com ONGS, autores e editores renomados nas áreas de educação e cultura. $\mathrm{O}$ critério para a oferta de produtos e serviços foi embasado principalmente na Lei de Direitos Autorais 9.610/98. Todos os conteúdos foram previamente autorizados pelos autores ou detentores dos direitos autorais, quando não eram conteúdos de domínio público.

Esta medida foi necessária em razão da BNB, por ser uma instituição recente e que está ainda em fase de "estruturação" de seus recursos humanos e materiais, não possuir volume significativo de conteúdos próprios para serem oferecidos em seu portal.

\section{BNB Comunidade e Jovem}

Outros dois segmentos importantes para a Biblioteca Nacional de Brasília foram atendidos no ambiente online: a comunidade e o jovem.

A BNB atrai diversos públicos para as suas instalações físicas que buscam o local para terem acesso à leitura, ao lazer e as diversas atividades abertas e gratuitas para o público em geral. Neste sentido, estudantes, donas de casa, trabalhadores e jovens, podem realizar de forma presencial seus estudos e leituras, apreciar exposições, participar de eventos, minicursos e assistir às palestras gratuitas que ocorrem mensalmente em seus espaços.

Pensando nestes públicos, a BNB reuniu, em dois sites - BNB Comunidade e BNB Jovem - conteúdo de qualidade com informações pertinentes. A seleção dos conteúdos para estes sites foi feita com o intuito de auxiliar as pessoas a resolverem problemas comuns do cotidiano por meio de informações úteis provenientes de fontes confiáveis. Além, é claro, de incentivar o hábito

\begin{tabular}{l|l|l|l|l|l|l} 
(C) Rev. digit. bibliotecon. cienc. inf. & Campinas, SP & v.11 & n.1 & p.93-110 & jan./abr. 2013 & ISSN 1678-765X \\
\hline
\end{tabular}


da leitura através das "dicas de leitura" e das informações sobre as coleções da biblioteca.

No subsite da "Comunidade", a BNB presta um serviço de informação utilitária, com informações voltadas para o público da terceira idade, para o turista que visita a Capital, para os jovens e adultos que desejam retomar os estudos e para os trabalhadores que buscam uma oportunidade de emprego ou curso de capacitação. Além disso, há também as dicas de leitura e informações detalhadas sobre os espaços e coleções que a biblioteca possui.

Para os jovens, o subsite "BNB Jovem" oferece informação recreativa e educacional. A preocupação principal foi desenvolver um subsite que mantivesse o jovem bem informado, mas que também fosse divertido e atraente. O objetivo da proposta foi tornar o jovem consciente e, posteriormente, um agente multiplicador de informação. Foram reunidas nas seções do site informações sobre o vestibular, dicas sobre pesquisas escolares, orientações seguras a respeito de temas que despertam a curiosidade nos jovens, como, por exemplo, sexualidade, drogas, saúde e segurança, além de informá-los sobre a programação cultural da biblioteca e da cidade.

\section{BNB Pesquisador}

O objetivo deste subsite é oferecer ao pesquisador produtos e serviços em literatura brasileira, artes, cultura, Ciência e Tecnologia e informações sobre instituições de fomento à pesquisa no Brasil e no exterior. Além disso, estão disponíveis documentos e bases de dados para auxiliá-lo no desenvolvimento de suas atividades científicas.

O subsite do Pesquisador conta com as seguintes seções: texto de Apresentação; informações sobre a implantação do Espaço do Pesquisador na BNB que ocupará o $4^{\circ}$ andar da Biblioteca Nacional de Brasília; e, referências para as principais fontes externas de pesquisa, tais como: Bases de Dados, eventos em Ciência e Tecnologia e Instituições de Pesquisa. 


\section{RESULTADOS OBTIDOS}

Através da ferramenta gratuita Google Analytics foi possível monitorar o desempenho do portal ao longo de 2009 até 2011. Esta ferramenta fornece informações valiosas a respeito do tráfego de dados do portal. Conteúdos mais acessados, número de visitantes, origem das visitas e tempo médio de permanência na página são algumas das informações obtidas através da ferramenta e que permitem o planejamento das ações em busca do sucesso do portal.

Para efeito de análise de desempenho do portal foi considerado o período de 2008 a 2011, distribuídos em três etapas que apresentam resultados referentes à sua primeira versão e desenvolvimento do projeto (2008/2009), ao primeiro ano de existência do novo portal (2009/2010) e, por fim, ao seu segundo ano de atividade na internet (2010/2011).

Ao analisarmos o desempenho da versão anterior do portal observou-se que, no período de dez./2008 (mês de inauguração da BNB e abertura ao público) a dez./2009, o portal recebeu um total de 45.277 visitas. É importante destacar que este período compreende à fase de elaboração e implementação do projeto da nova versão (Figura 3).

Painel de controle

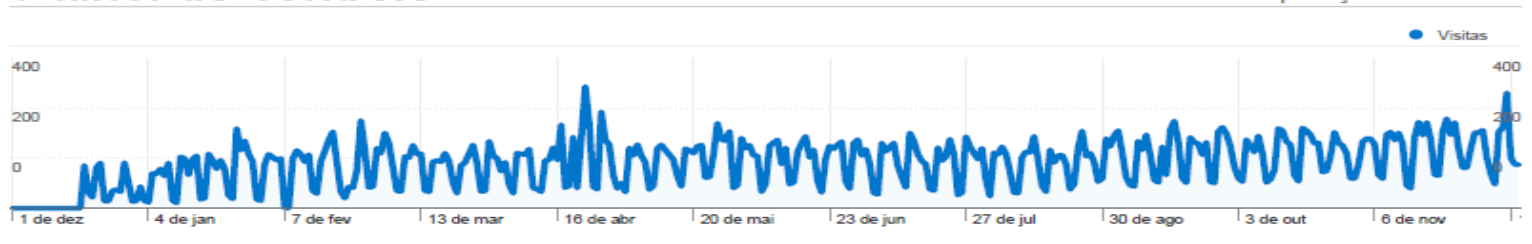

Uso do site

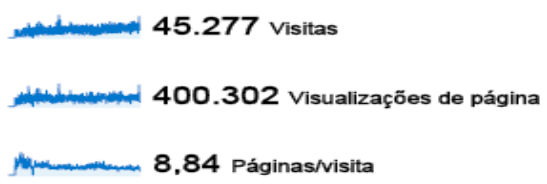

$0,47 \%$ Taxa de rejeições

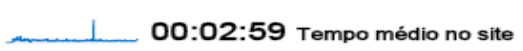

Hunaminim $51,85 \% \%$ Novas visitas

Figura 3 - Número de visitas à primeira versão da página da $\mathrm{BNB}^{6}$

\begin{tabular}{|c|c|c|c|c|c|}
\hline (c) Rev. digit. bibliotecon. cienc. inf. & Campinas, SP & v.11 & n.1 & p.93-110 & \begin{tabular}{|l|l} 
jan./abr. 2013 & ISSN 1678-765X \\
\end{tabular} \\
\hline
\end{tabular}


No período seguinte, correspondente a dez./2009 a dez./2010, já com a nova versão online, observou-se um aumento de mais de $100 \%$ no volume de acessos, perfazendo um total de 92.423 visitas, com tempo médio de permanência na página de 2 minutos. Este foi o primeiro ano de existência do novo portal, cujo lançamento oficial ocorreu durante as comemorações de aniversário de um ano da BNB (Figura 4).

\section{Painel de controle}

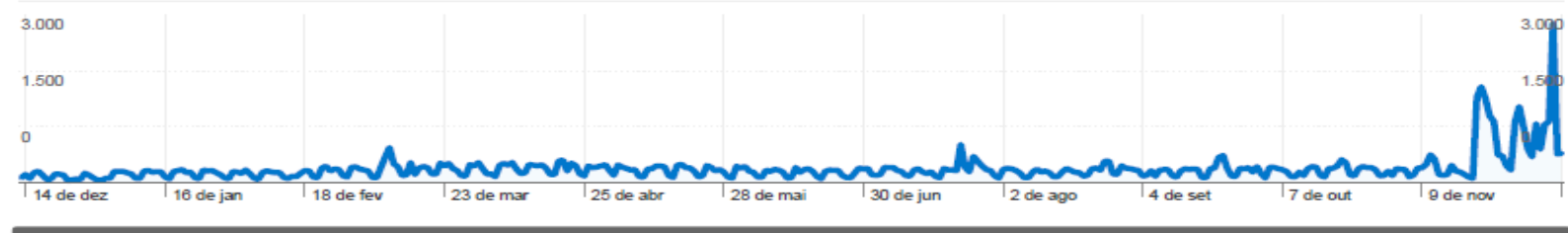

\section{Uso do site}

92.423 Visitas

239.837 Visualizaçöes de página

2,59 Páginas/visita
$61,93 \%$ Taxa de rejeiçöes

00:02:31 Tempo médio no site

$67,81 \% \%$ Novas visitas

Figura 4 - Número de visitas após o lançamento oficial do novo Portal $^{7}$

O terceiro período, objeto de comparação do presente estudo, compreendeu dez./2010 até set./2011, tendo sido registrados 208.979 visitas, ou seja, o portal, em seus dois anos de existência online, registrou um crescimento de mais de $100 \%$ de acessos, além do tempo de permanência que saltou de cerca de 2 minutos para 3 minutos, com índice positivo de novas visitas $(66 \%)$.

\begin{tabular}{|c|c|c|c|c|c|}
\hline (C) Rev. digit. bibliotecon. cienc. inf. & Campinas, SP & v.11 & n.1 & p.93-110 & \begin{tabular}{l|l} 
jan./abr. 2013 & ISSN 1678-765X \\
\end{tabular} \\
\hline
\end{tabular}




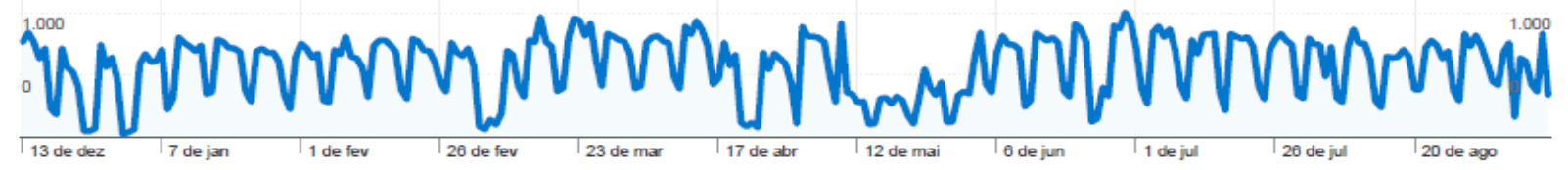

\section{Uso do site}

ymopmily 208.979 Visitas

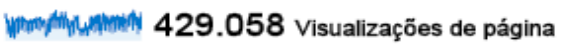

2,05 Páginas/visita

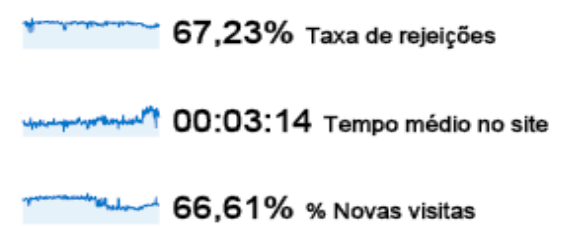

$66,61 \% \%$ Novas visitas

Figura 5 - Número de visitas ao Portal após um ano e meio de permanência online ${ }^{8}$

Outro dado relevante diz respeito aos conteúdos do portal. Um dos principais objetivos para a mudança do layout da página da BNB era dar maior destaque a alguns conteúdos que não eram tão explorados pelos visitantes. Na versão anterior, dava-se maior destaque às notícias produzidas pela assessoria de comunicação, que ocupava grande parte do portal. Com a nova página da biblioteca observamos uma mudança no comportamento dos visitantes que, agora, acessam mais as informações sobre os espaços disponíveis na BNB, os produtos e serviços, acervo e os eventos realizados na instituição.

O monitoramento do desempenho do portal é analisado em reuniões mensais com o objetivo de avaliar as estatísticas fornecidas pelo Google Analytics e discutir sobre a atualização de conteúdos. O feedback dos usuários também é medido por meio dos e-mails do Fale Conosco e compartilhado por toda a equipe.

Ao longo de 2010 e 2011, outras ferramentas foram incorporadas ao portal com o objetivo de potencializar o número de acessos como a implantação dos canais da BNB nas mídias sociais Facebook, Twitter e Youtube e o envio de newsletter aos usuários cadastrados. Para 2012, está

\begin{tabular}{|c|c|c|c|c|c|}
\hline (c) Rev. digit. bibliotecon. cienc. inf. & Campinas, SP & v.11 & n.1 & p.93-110 & \begin{tabular}{l|l} 
jan./abr. 2013 & ISSN 1678-765X
\end{tabular} \\
\hline
\end{tabular}


prevista a atualização do gerenciador de conteúdo Joomla para uma versão mais moderna e que tenha mais aplicativos que favoreçam a interatividade e o compartilhamento de informações, além da oferta de novos serviços, dentre os quais a abertura do catálogo online para consulta dos internautas.

\section{CONSIDERAÇÕES FINAIS}

Bernardino e Suaiden (2011, p. 139) propõem que o papel da biblioteca na sociedade da informação será efetivado quanto esta estabelecer relações estreitas com a sua comunidade usuária, tendo-a como foco principal de atuação. Neste sentido, as seções citadas acima representam a preocupação da instituição em atender as necessidades de informação de seus diversos públicos, por meio de seu portal, revelando ainda que a Biblioteca Nacional de Brasília é uma instituição transparente, de vanguarda e que participa ativamente da vida cultural da cidade, indo além da oferta de livros à população.

Durante o ano de 2009, inúmeras discussões e pesquisas em outras páginas na internet serviram de norte para a escolha dos conteúdos ofertados aos internautas e da arquitetura da homepage, bem como a definição de Boyce (2000 apud SIMEÃO, 2006, p. 157) sobre portais como aglutinadores de informações relevantes, sinalizando o funcionamento de uma comunicação em rede, interativa e diferenciada.

Por fim, a despeito dos problemas financeiros e da falta de pessoal especializado, o grupo conseguiu desenvolver um portal leve, de design moderno, com conteúdos interativos, interconectados e hipermidiáticos no contexto da comunicação extensiva, definida por Simeão (2006, p. 52) como a interação de emissores e receptores com uma lógica hipertextual, pontual e objetiva em suas metas, mas efêmera, sem estoques e em constante mutação.

A partir da experiência e da vivência da equipe que desenvolveu o novo portal da BNB, de forma multidisciplinar e coletiva, esperamos, em breve, oferecer mais conteúdos multimídia, novos produtos e serviços, e habilitar ferramentas que permitam uma interatividade mais efetiva

\begin{tabular}{|c|c|c|c|c|c|}
\hline (C) Rev. digit. bibliotecon. cienc. inf. & Campinas, SP & v.11 & n.1 & p.93-110 & ISSN 1678-765X \\
\hline
\end{tabular}


entre a instituição e os seus públicos, inserindo a BNB definitivamente no cenário da informação na web.

\section{REFERÊNCIAS}

AMARAL, Sueli Angelica do; GUIMARÃES, Tatiara Paranhos. Sites das bibliotecas universitárias brasileiras: estudo das funções desempenhadas, Brasil. In: SEMINÁRIO NACIONAL DE BIBLIOTECAS UNIVERSITÁRIAS, 12., 2002, Recife, Anais.... Recife: UFPE, 2002.

BERNARDINO, Maria Cleide Rodrigues; SUAIDEN, Emir José. Imagem da Biblioteca pública na Sociedade da Informação. InCID: R. Ci. Inf. e Doc., Ribeirão Preto, v. 2, n. 1, p. 130-142, jan./jun. 2011.

BRASIL. Lei n ${ }^{\circ}$ 9.610, de 19 de fevereiro de 1998. Altera, atualiza e consolida a legislação sobre direitos autorais e dá outras providências. Disponível em:

<http://www.planalto.gov.br/ccivil_03/leis/L9610.htm>. Acesso em: 15 set. 2011.

MIRANDA, Antônio. BNB no ciberespaço. Brasília, 2009. Disponível em: <http://www.bnb.df.gov.br/index.php/conheca-a-bnb $>$. Acesso em: 11 set. 2011.

A biblioteca híbrida na estratégia da inclusão digital na Biblioteca Nacional de Brasília.

Inclusão Social, v. 3, n. 1, p. 17-23, out. 2007/ mar. 2008.

SIMEÃO, Elmira. Comunicação extensiva e informação em rede. Brasília: Universidade de Brasília, Departamento de Ciência da Informação e Documentação, 2006. (Comunicação da informação digital; 2).

SUAIDEN, Emir. A biblioteca pública no contexto da sociedade da informação. Ciência da Informação, v. 29, n. 2, p. 52-60, maio/ago. 2000.

GOOGLE ANALYTCS. Disponível em: 〈https://www.google.com/analytics〉. Acesso em: 15 set. 2011. 


\section{Como citar este relato:}

SILVA, Vanessa Barbosa da; SALIM, Flávia Marta Camarano.Portal na BNB: relato da experiência do processo de criação, organização e planejamento do Portal da Biblioteca Nacional de Brasília. Rev. digit. bibliotecon. cienc. inf., Campinas, SP, v.11, n.1, p.93-110, jan./abr. 2013. ISSN 1678-765X. Disponível em: <http://www.sbu.unicamp. br/seer/ojs/índex.php>. 